\title{
The virtual university
}

\author{
Digital tools for e-learning and remote learning are becoming an increasingly important tool for \\ teaching at universities
}

\author{
Philip Hunter
}

$\mathrm{E}$ -learning in higher education started as early as the Internet but for long remained a mere adjunct that added little to the traditional university educational fabric woven around lectures, coursework and written examinations. But the pace of digitization in education is accelerating thanks to the widespread availability of fast broadband and wireless networks together with portable devices from laptops to tablets to smartphones. Digital learning methods are penetrating curricula not just at universities but across the whole spectrum of education from kindergarten upwards. As more universities explore the potential of online seminars, lectures and lab courses, they face a set of new challenges, from technical problems to financing the development of highquality educational material and devising strategies about how to efficiently interact with students.

\section{"Digital learning methods are penetrating curricula not just at universities but across the whole spectrum of education from kindergarten upwards."}

The catalyst for e-learning at university level was the introduction of so-called MOOCs (Massive Open Online Courses) by several leading US universities, notably Harvard, Yale and Stanford, in 2012. This prompted a flurry of activity in Europe to develop a strategic approach to university online learning. The European Commission, in September 2013, published its "Opening up Education” action plan to boost digital innovation across all of education. In July
2014, the League of European Research Universities (LERU) published a seminal paper, "Online Learning at Research-Intensive Universities” (http://www.leru.org/files/ publications/LERU_AP16_Online_Learning at_RIUs_final.pdf), in response to the now mushrooming MOOCs movement. The key message to universities was not to dive headlong into online learning but first develop a proper vision for education that incorporates online tools. "In summary it was saying that if and when universities adopt an online strategy, including MOOCs and SPOCs (Small Private Online Courses) and other online courses you share with the world, it's crucial that policy is part of the bigger strategic vision”, said Simone Buitendijk, ViceRector Magnificus at Leiden University in the Netherlands and a participant in the panel at the launch of the LERU paper. "It's really important you put money and effort into any online innovation and think about what the strategy is, both in research and innovation". The subtext of the report though is that major universities do not really have a choice but to embrace online learning. "The development of MOOCs and SPOCs has created a huge impulse for development of online learning in general, especially blended learning, and different technologies that are really changing our pedagogy and the tools we're using for our teaching”, Buitendijk said.

\section{"... major universities do not really have a choice but to embrace online learning"}

These tools are not just MOOCs or educational videos posted on video channels. E-learning extends beyond traditional learning and encompasses a whole range of digital forms from merely recording lectures to sophisticated tools for interacting with tutors, collaborating among students and enabling peer assessment of coursework. There is also a distinction between distance learning and online methods to augment traditional on-campus lectures, laboratory work or seminars. While MOOCs have renewed interest in distance learning as a medium for reaching out to a larger base, the principle application of online methods lies in on-campus education as it gives greater scope for experiment and innovation, according to Buitendijk. "Online learning is a laboratory setting almost for testing different pedagogies that in the past we just didn't have", said Buitendijk. "It's very difficult to randomise a classroom of students for testing, but much less so with a group attending an online course".

One clear trend that is being considered by some universities is to phase out traditional lectures for large numbers of students to make these available online only. "If you have lecture halls full of 300 or 400 students, those you may be able to put online and let students watch them at home and use that freed up time for something else”, said Buitendijk. Manchester University in the UK is trying to establish an optimum blend between direct face-to-face interaction and online teaching, according to Richard Reese, Associate Vice President for Teaching, Learning and Students. "We promote a very close interaction between academics and students throughout their course", he explained. "Online interaction can be more frequent, with far more possibilities, but is less direct".

Manchester believes that digital technology can reinvigorate the traditional lecture, 
rather than replacing it, by introducing more interaction and a degree of individual response. The university decided to exploit the fact that just about all students now bring smartphones, tablets or laptops to lectures and designed an app called mbclick that enables real-time response and feedback. It allows lecturers to present quizzes or individual questions that students can respond to immediately via their devices. This has proved so successful that the app has now been licensed by a number of other universities and is also being used for a more radical reform of some lectures around interactive quiz sessions that may not require students to attend in person.

《

... the principle application of online methods lies in oncampus education as it gives greater scope for experiment and innovation..."

$\mathrm{T}$ his app has also helped Manchester University to gauge the attitude and response of students to online learning. After a trial, more than $90 \%$ of students indicated that it would improve their overall satisfaction with the course. According to the university, students enjoyed traditional lectures much more as a result of the interactivity and ability to participate in the class without having to raise a hand and interrupt the lecturer. It also helped lecturers to assess which aspects of a topic they need to dwell on because it had not been properly understood.

The natural sciences often include laboratory work and experiments, and here too, online learning is making a great impact. Various institutions had pioneered distance learning before online methods were even available. One of the most innovative on this front has been the UK's Open University, founded in 1969 for predominantly offcampus courses available in principle to anybody in the world. "The old Open University Science Foundation Course used to see chemistry sets and all sorts of equipment shipped through the post to students to set up in their kitchen”, noted Jonathan Baldwin, Director of Teaching and Learning at the Institute of Continuing Education at the University of Cambridge, UK. "Then a long summer school gave experience in a 'real university lab”, added Baldwin, who did his masters at the Open University. "A lot of the people who did that course went on to be scientists and teachers".

Baldwin's point is that direct involvement in shared practical sessions may not be essential in all cases. Online learning can enable students to participate indirectly in experiments that, for various reasons, they cannot attend in person, as was pointed out by Xavier Prats, Director General of EAC, the EU's Directorate for Education \& Culture. "Technology can help to ensure a multidisciplinary approach and can provide virtual experiments where real ones might not be possible", he said. "Digital and online tools can also help to connect the classroom and actual practice, for example, when learners can interact directly with research institutes or work directly with current research data”.

\section{"Online learning can enable students to participate indi- rectly in experiments that, for various reasons, they cannot attend in person...'}

The Open University has already responded to the challenge by researchbased institutions with on-campus laboratory facilities through its "OU Anywhere" app for smartphones and tablets. On top of this app, it developed a package called "The Open Science Laboratory" that provides access to facilities and data from real physical instruments and equipment, enabling students to carry out authentic and rigorous science investigations, commented a spokesperson for Open University. It makes the entire undergraduate prospectus available online. "The app enables students to download digital versions of the OU textbooks, DVDs and audio CDs they receive in the post, allowing them to study at home, in the office, or on the move", said the spokesperson, adding that it has proved popular with students.

Online learning can also enrich field work according to Alastair Creelman, Vice President of the European Foundation for Quality in eLearning (EFQUEL). "I listened to an example recently where instead of hiring a bus and taking students out on a field trip, they gave them a scenario and things they had to investigate and they were told to go somewhere they knew well that fits this description. Then they were told to do these things and record it using mobile phones or tablets or whatever, film the things you see, write on your blog and so on", he explained. "That meant that when they came back to class they had a wealth of material that was shared among the whole class. They had a much more meaningful field trip".

Whether field trips or lab work, online methods are starting to play a direct role in general practical work. Bristol University in the UK set up its eBiolabs in 2009 with the initial aim of reducing the more mundane or administrative aspects of practical research so that students could spend more lab time doing experiments rather than being issued instructions. "This was taking flip learning generally aimed at lecture material where students are given a video to watch or material to read in advance to make teaching more efficient, and applying it to the lab", explained Gus Cameron, eBiolabs' director. As with e-learning in general, it is difficult to quantify the impact of eBiolabs on academic attainment, Cameron commented. "But student satisfaction has gone through the roof, having increased by at least double digits in every survey we have done. Then, admittedly anecdotally, staff report having much better conversations with students about the science and results of experiments", he said. "It's been a real success and gone right through the Faculty and out into engineering, dentistry and clinical skills".

Yet eBiolabs has only just begun to realize its potential for changing the scope of practicals themselves, according to Cameron. "It's really only just beginning. Many of our practicals are still too tick box and don't allow students to experiment", he said. "We want to make them more discovery based and allow students to design their own experiments". As one early example, first-year students have been taught the techniques to analyse vitamin $\mathrm{C}$ as preparation for designing experiments. "We give them lots of examples of how they might approach it and this allows them to prepare and have discussion forums that tutors can intervene in as well”, Cameron explained.

$\mathrm{t}$ the end, however, it all comes
down to finances, Cameron
commented. "There's been lots and 
lots of interest from other universities but the biggest challenge they have is raising funding, because developing content is expensive. Academics have to work with specialist designers, who have to be paid. We had to convince people of the benefits of our approach, and fund it in-house. There are no major grants we could apply to". But once the benefits had been demonstrated, the university made a major commitment to eBiolabs, said Cameron, and funding is no longer an issue. Generally, funding of expertise is a significant ingredient for e-learning. Some universities are training existing staff to act as course developers, while others like Manchester University have decided to hire specialist online course developers. "These people are individuals who have a great deal of experience in construction and delivery of online learning, providing elbow support for academic staff", said Reese.

\section{« ... specialists are needed to develop and design external online courses such as MOOCs and SPOCs, not least because the university's reputation is on the line"}

Moreover, specialists are needed to develop and design external online courses such as MOOCs and SPOCs, not least because the university's reputation is on the line. "If you put MOOCs out there and everyone with a PC on the globe can watch them and quality is insufficient, then that is a huge PR risk for the university", said Buitendijk. There has already been one celebrated case of such reputational damage in the short history of MOOCs. In February 2013, the Georgia Institute of Technology in Atlanta, GA, USA, decided to suspend its MOOC "Fundamentals of online education”, which had 40,000 participants, after a variety of widely reported technical problems.

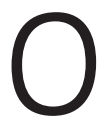
ver the long term, there is potential for universities to make money from external courses and obtain an additional source of revenue, but there is little immediate prospect of this, according to Buitendijk. "There's the potential for making money, but that's really far away", she said. "If you're going to make money from MOOCs it's only going to be from topics with huge groups of learners who are willing to pay money for a certified diploma”. Moreover, charging for online course creates a potential conflict of interest for universities if they dumb down their courses and do not play to existing strengths. "Only to put on topics that will generate revenue is not what we're about as a university", said Buitendijk. "At Leiden we're developing MOOCs and SPOCs for myriad reasons and one very important one is the emancipation and innovation in education that can take place because of these developments".

One unintended consequence of external online courses from traditional universities could be mounting competition for dedicated distance learning institutions. "That's what's happening, open universities are having a problem now, because the regular universities are starting to do the things they've been doing for years and sometimes they have more prominent researchers they can use for development of online courses", said Buitendijk. "But that's not why we're doing it, to compete with open universities".

There is also the risk of getting carried away by technology and losing sight of teaching values. “As anyone who's sat through death-by-bullet-point Powerpoint presentations will tell you, technology does not trump good teaching", said Baldwin. "It might aid it. It might afford new methods. But I think I'd be right in saying universities have spent far more on technology in recent years than they have on developing and rewarding good teaching, and that's completely the wrong way round". Baldwin also highlighted the role of students, who vary greatly in their response to e-learning. "Online learning depends on the student far more than I think many are comfortable admitting", he said. "For the last forty years one of the dominant ideas in teaching and learning has been the concept of learning styles, the idea that different students learn differently. The idea gets oversimplified sometimes, which leads to counter arguments, but at its heart it's common sense. So it's common sense too to say that some people don't learn online as well as othersforget the issue of 'can they use the technology' which is, of course, important. It's far more fundamental than that. Partly it's tied to the way the online learning is presentedif it's just a lot of text on a screen, not everyone likes reading that way. But if it's an animation, or simulation, maybe that's a better way of getting across a concept than describing it in text”.

This point is picked up by Johnson at Illinois Online Net, who argued that online learning should not be seen as a panacea. "It is absolutely essential to remember that the heterogeneity of learners involved in any particular experience makes it a certainty that any single teaching strategy will be off point for almost everyone", he said. "For some, online learning is precisely what we need most and is that singular life raft in an ocean of isolation. For others it presents challenges and a litany of priority choices for which we are often illprepared". He gave the example of students suffering from autism or others who just find social interaction difficult, for whom online learning is a revelation, avoiding the isolation of the classroom. But for people who learn best through collaboration and working with others, online learning is a challenge. The key is to make online learning flexible and exploit its potential for remote collaboration, which could benefit everybody. 